(c) Elsevier/North-Holland Scientific Publishers Ltd.

\title{
POLYCHLORINATED BIPHENYLS AS INDUCERS OF HEPATIC MICROSOMAL ENZYMES: EFFECTS OF DI-ORTHO SUBSTITUTION
}

\author{
A. PARKINSON, L.W. ROBERTSONa , LORNA SAFE and S. SAFE* \\ The Guelph-Waterloo Centre for Graduate Work in Chemistry, Department of Chemistry, \\ University of Guelph, Guelph, Ontario N1G 2 W1 (Canada) and a School of Public Health, \\ The University of Michigan, Ann Arbor, MI 48109 (U.S.A.)
}

(Received October 1st, 1980)

(Accepted December 10th, 1980)

\section{SUMMARY}

All of the 13 possible polychlorinated biphenyl (PCB) isomers and congeners substituted at both para positions, at least two meta positions (but not necessarily on the same ring) and at two ortho positions have been synthesized and tested as rat hepatic microsomal enzyme inducers. The effects of these compounds were evaluated by measuring microsomal benzo[a]pyrene $(\mathrm{B}[a] \mathrm{P})$ hydroxylase, 4-chlorobiphenyl (4-CBP) hydroxylase, 4-dimethylaminoantipyrine (DMAP) $\mathrm{N}$-demethylase and NADPH-cytochrome $c$ reductase activities, the cytochrome $b_{5}$ content and the relative peak intensities and spectral shifts of the carbon monoxide( $\mathrm{CO}$ )- and ethylisocyanide(EIC)-difference spectra of ferrocytochrome $P-450$. The results were compared to the effects of administering phenobarbitone (PB), 3 methylcholanthrene (MC) and PB plus MC (coadministered). At dose levels of $150 \mu \mathrm{mol} \cdot \mathrm{kg}^{-1}$, all of the PCB congeners, except $2,3^{\prime}, 4,4^{\prime}, 5^{\prime}, 6$-hexachlorobiphenyl, significantly enhanced hepatic microsomal cytochrome $P-450$ content, B [a]P hydroxylase and/or DMAP $N$-demethylase activities compared to the control (corn oil-treated) animals. Only 5 of these compounds, namely $2,3,4,4^{\prime}, 5,6$-hexa-, $2,2^{\prime}, 3,3^{\prime}, 4,4^{\prime}$-hexa-, $2,2^{\prime}, 3^{\prime}, 4,4^{\prime}, 5$-hexa-, $2,3,3^{\prime}, 4,4^{\prime}, 6$-hexaand $2,2^{\prime}, 3,3^{\prime}, 4,4^{\prime}, 5$-heptachlorobiphenyl, enhanced microsomal $\mathrm{B}[a] \mathrm{P}$ hydroxylase, 4-CBP hydroxylase, NADPH-cytochrome $c$ reductase and DMAP $N$-demethylase activities in a manner consistent with a mixed pattern of induction. The results suggest that $\mathrm{PCB}$ isomers and congeners substituted at both para positions, at least two meta positions, at two ortho positions and containing a 2,3.4-trichloro substitution pattern on one ring are mixed-

*To whom reprint requests should be sent.

Abbreviations: $\mathrm{B}[a] \mathrm{P}$, benzo[a] pyrene; 4-CBP, 4-chlorobiphenyl; $\mathrm{CO}$, carbon monoxide; DMAP, 4-dimethylaminoantipyrine; EC, electron capture; EIC, ethylisocyanide; GLC, gas liquid chromatography; MC, 3-methylcholanthrene; PB, phenobarbitone; PMR, proton magnetic resonance; TCDF, 2,3,7,8-tetrachlorodibenzofuran; TLC, thin-layer chromatography. 
type inducers; in addition the effects of $2,3,4,4^{\prime}, 5,6$-hexachlorobiphenyl were also consistent with a mixed pattern of induction.

\section{INTRODUCTION}

Structure-activity rules for PCBs as inducers of hepatic microsomal enzyme activity in the immature male rat support the following correlations [1]: (1) There are no apparent rules for PB-type inducers due to the structurally-diverse PCB isomers and congeners which fall into this class of compounds. (2) MC-type inducers must be substituted at both para positions and at least two meta positions but not necessarily on the same phenyl ring. (3) With one exception, i.e., $2^{\prime}, 3,4,4^{\prime}, 5,5^{\prime}$-hexachlorobiphenyl, the substitution of one ortho substituent on the nucleus of the four possible MC-type inducers defined in (2) does not abolish this type of activity but give a series of mixed-type inducers.

The results obtained for $2^{\prime}, 3,4,4^{\prime}, 5,5^{\prime}$-hexachlorobiphenyl initially suggested that this compound was a PB-type inducer evidenced by enhanced hepatic microsomal $\mathrm{B}[a] \mathrm{P}$ hydroxylase and DMAP $N$-demethylase activities and cytochrome $P-450$ content with negligible qualitative changes in the reduced cytochrome $P-450 / \mathrm{CO}$ - and EIC-difference spectra compared to control rats [2]. However a more detailed study indicated that $2^{\prime}, 3,4,4^{\prime}, 5,5^{\prime}$-hexachlorobiphenyl is a novel inducer [3,4].

Previous reports have suggested that 3 PCB isomers, $2,2^{\prime}, 4,4^{\prime}, 5,5^{\prime}-, 2,2^{\prime}, 3,3^{\prime},-$ $4,4^{\prime}-$ and $2,2^{\prime}, 3^{\prime}, 4,4^{\prime}, 5$-hexachlorobiphenyl, which contain the structural prerequisites defined in (2) plus two ortho substituents on different rings, may also be mixed-type inducers $[5,6]$. From a re-investigation of the effects of $2,2^{\prime}, 4,4^{\prime}, 5,5^{\prime}$-hexachlorobiphenyl, Goldstein et al. [7] concluded that this is a PB-type inducer and that the reported MC-type characteristics were due to trace contamination with highly active 2,3,7,8-tetrachlorodibenzofuran (TCDF) which was formed during the preparation of this compound via the copper-catalyzed Ullmann coupling of 2,4,5-trichloroiodobenzene. We have synthesized, purified and evaluated the effects of $2,2^{\prime}, 3,3^{\prime}, 4,4^{\prime}$ - and $2,2^{\prime}, 3^{\prime},-$ 4,4',5-hexachlorobiphenyl as microsomal enzyme inducers [8] and both compounds elicited responses consistent with mixed-type inducers as reported by Stonard and Greig [6].

This paper describes the synthesis and mode of microsomal enzyme induction of all those PCB isomers and congeners which possess the structural prerequisites for the strictly MC-type inducer (i.e., rule (2)) plus two ortho chloro substituents. The inductive effects of these 13 possible PCBs were compared to those elicited by $\mathrm{PB}, \mathrm{MC}$ and $\mathrm{PB}+\mathrm{MC}$ (coadministered) on microsomal $\mathrm{B}[a] \mathrm{P}$ hydroxylase, 4-CBP hydroxylase, DMAP $N$-demethylase and NADPH cytochrome $c$ reductase activities, the cytochrome $b_{5}$ content and the intensities and absorption maxima of the CO- and EIC-difference spectra of ferrocytochrome $P-450$. The structures of the strictly MC-type inducers (namely $3,4,4^{\prime}, 5$-tetra-, $3,3^{\prime}, 4,4^{\prime}$-tetra-, $3,3^{\prime}, 4,4^{\prime}, 5$-penta- and $3,3^{\prime},-$ 
<smiles>Clc1ccc(C2=CC(Cl)C(Cl)C=C2)cc1</smiles><smiles>Clc1cc(Cl)c(-c2ccccc2Cl)cc1Cl</smiles><smiles>Clc1ccc(-c2cc(Cl)c(Cl)c(Cl)c2Cl)cc1</smiles><smiles>Clc1cc(Cl)cc(-c2cc(Cl)cc(Cl)c2)c1</smiles><smiles>Clc1ccc(-c2ccc(Cl)c(Cl)c2)cc1</smiles><smiles>Clc1cccc(-c2ccc(Cl)c(Cl)c2Cl)c1Cl</smiles><smiles>Clc1ccc(Cl)c(-c2ccc(Cl)c(Cl)c2Cl)c1</smiles><smiles>Clc1ccc(Cl)c(-c2cc(Cl)ccc2Cl)c1</smiles><smiles>Clc1ccc(-c2ccc(Cl)c(Cl)c2)cc1</smiles><smiles>Clc1ccc(-c2ccc(Cl)c(Cl)c2)cc1</smiles><smiles>Clc1ccc(-c2ccc(Cl)c(Cl)c2Cl)c(Cl)c1Cl</smiles><smiles>ClC1=CC(c2cc(Cl)c(Cl)cc2Cl)=CC(Cl)C1Cl</smiles><smiles>Clc1ccc(C2=CC(Cl)C(Cl)C(Cl)C2)c(Cl)c1</smiles><smiles>Clc1ccc(-c2ccc(Cl)c(Cl)c2)cc1</smiles><smiles>Clc1cc(Cl)cc(-c2cc(Cl)c(Cl)cc2Cl)c1</smiles><smiles>ClC1=C(Cl)C(c2c(Cl)c(Cl)c(Cl)c(Cl)c2Cl)CCC1Cl</smiles>

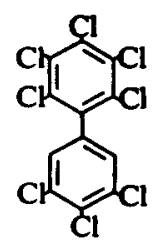

Fig. 1. Structures of the 13 possible di-ortho substituted derivatives derived from the 4 MC-type PCB inducers (the di-ortho compounds are shown in the same order as they appear in Tables I and II).

$4,4^{\prime}, 5,5^{\prime}$-hexachlorobiphenyl) and their 13 possible di-ortho derivatives are shown in Fig. 1.

\section{MATERIALS AND METHODS}

\section{Synthesis and purification of PCB isomers and congeners}

4-Chloroaniline, 2,4-dichloroaniline, 3,4-dichloroaniline, 2,3,4-trichloroaniline, 2,4,5-trichloroaniline, 3,4,5-trichloroaniline, 2,3,4,5-tetrachloroaniline, 1,2,3-trichlorobenzene, 1,3,5-trichlorobenzene, 1,2,3,4-tetrachlorobenzene, $1,2,3,5$-tetrachlorobenzene and pentachlorobenzene were purchased from the Aldrich Chemical Company and amyl nitrite was obtained from Pfaltz 


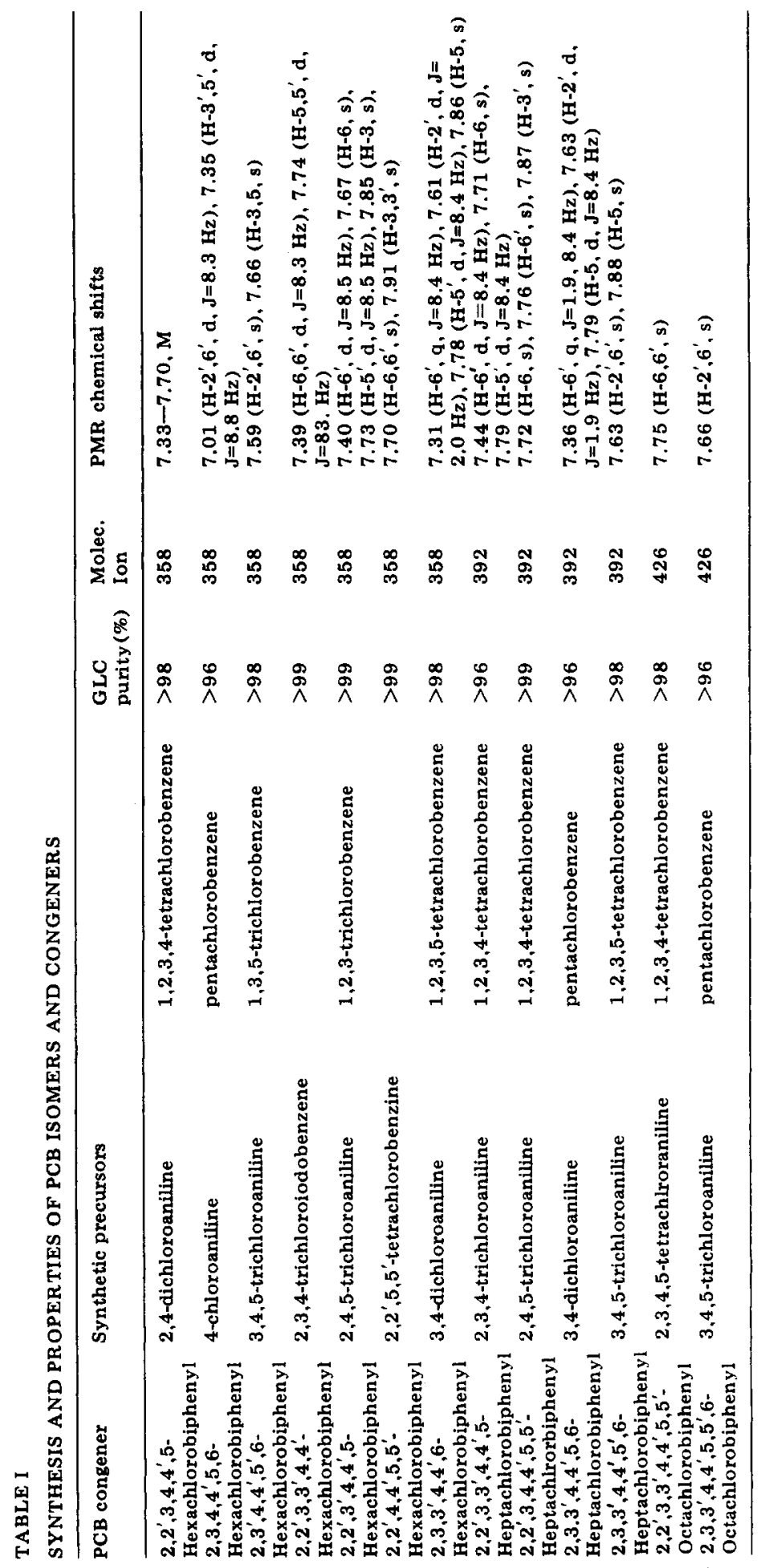


and Bauer, Inc. $2,2^{\prime}, 4,4^{\prime}, 5,5^{\prime}$-Hexa- and $2,2^{\prime}, 3,3^{\prime}, 4,4^{\prime}$ 'hexachlorobiphenyl were synthesized from $2,2^{\prime}, 5,5^{\prime}$-tetrachlorobenzidine and 2,3,4-trichloroiodobenzene, respectively, as described $[2,8]$. The remaining PCB isomers and congeners were synthesized by the Cadogan coupling [9] of the appropriate chlorinated aniline (10-15 mmol) in excess chlorinated benzene (200-300 $\mathrm{mmol})$ in the presence of a slight excess of amyl nitrite $(20-25 \mathrm{mmol})$ as summarized in Table $\mathrm{I}$. The reactions were performed at $110-125^{\circ} \mathrm{C}$ with rapid stirring for $18 \mathrm{~h}$ followed by removal of the excess chlorinated benzene in vacuo. The products were absorbed on neutral alumina which was added to a Florisil/neutral alumina column and the crude PCB product(s) eluted with petroleum spirit (b.p. $30-60^{\circ} \mathrm{C}$ ). The crude product(s) were purified by preparative thin-layer chromatography (TLC) as described [10] and the purified congeners recrystallized from methanol and their structure confirmed by their mass and proton magnetic resonance (PMR) spectra as summarized in Table I. The gas-liquid chromatographic (GLC) purities were determined using a Hewlett-Packard model 5710 gas chromatograph equipped with a flame ionization or ${ }^{63} \mathrm{Ni}$ electron capture (EC) detector using an $0.6 \mathrm{~cm} \times$ $1.2 \mathrm{~m}$ glass column packed with $3 \%$ OV 101 on Ultrabonded Carbowax $20 \mathrm{M}$ (80-100 mesh, RFR Corporation).

\section{Biochemicals}

Cytochrome $c$ (horse heart, Type III) NADP + NADPH, glucose 6-phosphate, D-glucose-6-phosphate dehydrogenase (Baker's yeast), $\mathrm{MC}, \mathrm{B}[a] \mathrm{P}$ and EIC were purchased from Sigma Chemical Company; DMAP and CO were obtained from Aldrich Chemical and Matheson companies respectively and sodium $\mathrm{PB}$ was supplied by the dispensing pharmacy, Ontario Veterinary College, Guelph. $\left[{ }^{3} \mathrm{H}\right] \mathrm{B}[a] \mathrm{P}$ was purchased from New England Nuclear, dissolved in hexane and washed with $0.5 \mathrm{M} \mathrm{NaOH}$ to extract oxidized products and further purified by Florisil column chromatography using petroleum ether (b.p. $\left.30-60^{\circ} \mathrm{C}\right) /$ dichloromethane $\left(99: 1\right.$, v/v) as eluent. $4-\left[{ }^{3} \mathrm{H}\right] \mathrm{CBP}$ was prepared by base-catalysed tritium exchange of 4-CBP (New England Nuclear). Like $\mathrm{B}[a] \mathrm{P}$, the $4-\left[{ }^{3} \mathrm{H}\right] \mathrm{CBP}$ was washed with $\mathrm{NaOH}$, passed through a Florisil column using hexane as eluent followed by TLC developed in chloroform/acetic acid (99:1, v/v).

\section{Animal treatment and isolation of microsomes}

One-month-old male Wistar rats, average weight $100 \mathrm{~g}$, were housed in wire cages and allowed free access to Purina Certified Rodent Chow 5002 and water. The PCB isomers and congeners were dissolved in corn oil and doses of $150 \mu \mathrm{mol} \cdot \mathrm{kg}^{-1}$ were administered (with one exception) to at least 4 animals by intraperitoneal injection on days 1 and 3 . The animals were killed by cervical dislocation on day 6 . PB $\left(400 \mu \mathrm{mol} \cdot \mathrm{kg}^{-1}\right)$, dissolved in isotonic saline and $\mathrm{MC}\left(100 \mu \mathrm{mol} \cdot \mathrm{kg}^{-1}\right)$, dissolved in corn oil, were administered individually as well as coadministered to animals on days 1 and 2 and the animals killed on day 3 . Animals injected with a corresponding volume of corn oil $\left(5 \mathrm{ml} \cdot \mathrm{kg}^{-1}\right)$ served as controls which, along with $\mathrm{PB}-$, 
$M C$ - and $(\mathrm{PB}+\mathrm{MC})$-treated rats, were included in each experiment and no significant variation was observed from week to week. All animals were fasted over the last $24 \mathrm{~h}$ to lower liver glycogen levels.

The rat livers were perfused via the hepatic portal vein with ice-cold isotonic saline supplemented with EDTA $(0.1 \mathrm{mM})$. The blanched livers were transferred to pre-weighed, ice-cold solutions of sucrose-EDTA $(0.25 \mathrm{M}-0.1$ $\mathrm{mM}$ ) and the liver weights determined. The microsomal fraction was collected as a $100000 \times g$ pellet by further centrifugation of a $10000 \times g$ supernatant from the liver homogenate essentially as described [11].

\section{Assays}

In all assays the final concentration of microsomal protein was $1.0 \mathrm{mg}$ $\mathrm{ml}^{-1}$ as determined by the method of Lowry et al. [12]. The cytochrome $P-450$ content was determined by the method of Omura and Sato [13], from the CO-difference spectrum of dithionite-reduced microsomes using an extinction coefficient of $91 \mathrm{~cm}^{-1} \cdot \mathrm{mM}^{-1}$ between $A_{\max }$ and $A_{490}$. The EIC. difference spectrum was determined in a similar manner to the CO-difference spectrum except that EIC was added to the sample cuvette (final concentration $4.5 \mathrm{mM}$ ) instead of CO. The absence of a peak at $420 \mathrm{~nm}$ in the difference spectrum between carbonmonoxyhaemoglobin and oxyhaemoglobin (determined by bubbling $\mathrm{CO}$ through the sample cuvette using oxidised microsomes) indicated that the microsomes used in this study were essentially free from haemoglobin contamination. The concentration of cytochrome $b_{5}$ was determined from the difference spectrum between NADHreduced microsomes and oxidised microsomes [14] using the corrected extinction coefficient of $185 \mathrm{~cm}^{-1} \cdot \mathrm{mM}^{-1}$ [13]. All spectra were recorded on a Cary $118 \mathrm{C}$ spectrophotometer with a repetitive scan accessory. Holmium oxide was used to calibrate all spectra.

All other assays were performed as described [11]. The rate of oxidative $\mathrm{N}$-demethylation of DMAP was measured by quantifying the production of formaldehyde. The formaldehyde, trapped as the semicarbazone, was developed in double-strength Nash reagent. The rate of $\mathrm{B}[a] \mathrm{P}$ hydroxylation $[15,16]$ and 4-CBP hydroxylation [17] were both measured radiometrically by quantifying the base-soluble metabolites following hexane-extraction of the unreacted substrate. The activity of NADPH-cytochrome $P-450$ reductase was measured by the rate of reduction of cytochrome $c$. To prolong the linearity of the cytochrome $c$ reduction, samples with high NADPH-cytochrome $P-450$ reductase activity were diluted to a final microsomal protein concentration of $0.2 \mathrm{mg} \cdot \mathrm{ml}^{-1}$.

The values of $\mathrm{mg}$ microsomal protein $\mathrm{g} \cdot \operatorname{liver}^{-1}$ given in Table II are expressed as an increase over control rather than the absolute value. This is because a new Potter-Elvehjem homogeniser was installed before completion of the experiments and this increased the yield, but not the specific activity, of the microsomal protein.

The statistical significance between sample means of control and treated 


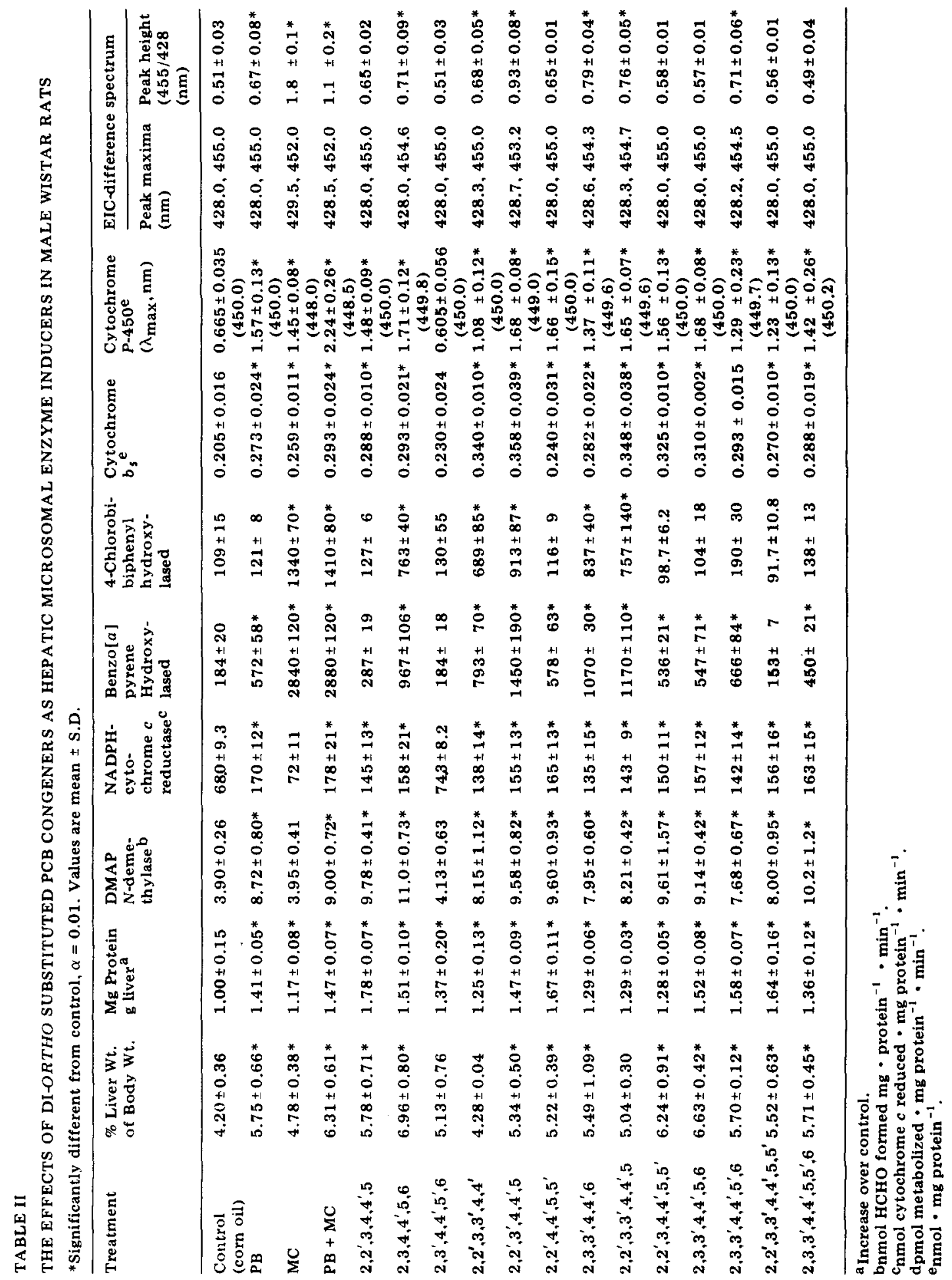


groups for each parameter studied was analysed by Dunnett's method for multiple comparisons with a control [18].

\section{RESULTS}

\section{Synthesis of $P C B$ congeners}

The identification of TCDF as an impurity in the preparation of 2,2',$4,4^{\prime}, 5,5^{\prime}$-hexachlorobiphenyl emphasises the need for synthetic routes which avoid the formation of active by-products. All of the crude reaction products used in this study were initially purified by chromatography through a Florisil/neutral alumina (approx. $1: 1, \mathrm{w} / \mathrm{w}$ ) column using petroleum ether (b.p. $30-60^{\circ} \mathrm{C}$ ) as eluent. The Cadogan coupling reaction has been used in our studies as the major synthetic method and involves the generation of a reactive electrophile (and possibly a radical) via diazotization of a chlorinated aniline. Although dimerization of a 3,4,5-trichlorophenyl moiety would form the potent MC-type inducer $3,3^{\prime}, 4,4^{\prime}, 5,5^{\prime}$-hexachlorobiphenyl, the results suggest that this is not an important pathway since $2,3^{\prime}, 4,4^{\prime}, 5^{\prime}, 6$ hexachlorobiphenyl (synthetically derived from 3,4,5-trichloroaniline) does not show any significant activity as a microsomal enzyme inducer. Preparative TLC, the final chromatographic purification, is used to separate products and also ensures the removal of potential MC-type PCB and TCDF contaminants from the desired PCB product.

The effects of $P B, M C$ and their coadministration $(P B+M C)$

Induction of cytochromes $P-450$ by $P B$ was characterised by (a) a proliferation of the endoplasmic reticulum (as indicated by an increase in the $\mathrm{mg}$ microsomal protein $\mathrm{g}$ liver $^{-1}$ ), (b) an increase in the activity of DMAP $N$ demethylase $(\times 2.2), \mathrm{B}[a] \mathrm{P}$ hydroxylase $(\times 3.1)$ and NADPH-cytochrome $c$ reductase $(\times 2.5),(\mathrm{c})$ an increase in the concentration of cytochrome $b_{5}$ and $P-450$ with the absorption maximum of the latter occurring at $450.0 \mathrm{~nm}$ and (d) an EIC-difference spectrum displaying two peaks at 428.0 and $455.0 \mathrm{~nm}$ with a $455: 428 \mathrm{~nm}$ peak height ratio of about 0.7 . In contrast to all other parameters measured, PB treatment failed to significantly increase the activity of 4-CBP hydroxylase. These features are shown in Table II.

In contrast, induction of cytochromes $P .448$ by $\mathrm{MC}$ was characterised by (a) negligible proliferation of the endoplasmic reticulum and no significant increase in the activity of either DMAP- $N$-demethylase or NADPHcytochrome $c$ reductase, (b) large increases in the activities of $\mathrm{B}[a] \mathrm{P}$ hydroxylase (X15) and 4-CBP hydroxylase (X12), (c) an increase in the concentration of cytochrome $b_{5}$ and $P-450$ with the absorption maximum of the latter shifted $2 \mathrm{~nm}$ downfield to $448.0 \mathrm{~nm}$ and (d) an EIC-difference spectrum with peak maxima at 429.6 and $450.0 \mathrm{~nm}$ and a ' $455: 428$ ' nm peakheight ratio of 1.9 .

In all cases the coadministration of $\mathrm{PB}$ with $\mathrm{MC}$ resulted in increases in enzymic activity and cytochrome concentration which were slightly greater than the corresponding increases evoked by either PB or MC alone. Following 
the coadministration of $\mathrm{PB}$ and $\mathrm{MC}$, the CO-difference spectrum showed maximum absorbance at $448.5 \mathrm{~nm}$, whilst the EIC-difference spectrum showed two peaks at 428.5 and $452.0 \mathrm{~nm}$ with a ' $455: 428$ ' $\mathrm{nm}$ peak height ratio of 1.2 . The spectral shifts elicited by the coadministration of $\mathrm{PB}$ and $\mathrm{MC}$ were slightly less than those evoked by the administration of $\mathrm{MC}$ alone. In general, the qualitative spectral characteristics displayed by (PB + $\mathrm{MC}$ )-induced microsomes were intermediate between $\mathrm{PB}$ - and $\mathrm{MC}$-induced microsomes.

\section{The effects of $P C B$ isomers and congeners}

The results summarized in Table II indicate that at dose levels of 150 $\mu \mathrm{mol} \cdot \mathrm{kg}^{-1}$ only $2,3^{\prime}, 4,4^{\prime}, 5^{\prime}, 6$-hexachlorobiphenyl did not significantly increase the concentration of hepatic, microsomal cytochrome $P-450$. The 1.5 - to 2.5 -fold increase in cytochrome $P-450$ content induced by all of the remaining $\mathrm{PCB}$ congeners was accompanied by comparable increases in DMAP $N$-demethylase and NADPH-cytochrome $c$ reductase activities. In other words, with the exception of the non-inducer $2,3^{\prime}, 4,4^{\prime}, 5^{\prime}, 6$-hexachlorobiphenyl, each PCB congener tested exhibited PB-type characteristics.

However, in contrast to $\mathrm{PB}$, five of the PCB congeners, namely $2,3,4,4^{\prime}$,5,6 -hexa-, $2,2^{\prime}, 3,3^{\prime}, 4,4^{\prime}$-hexa-, $2,2^{\prime}, 3^{\prime}, 4,4^{\prime}, 5$-hexa,- $2,3,3^{\prime}, 4,4^{\prime}, 6$-hexa- and $2,2^{\prime}, 3,3^{\prime}, 4,4^{\prime}, 5$-heptachlorobiphenyl, induced 4-CBP hydroxylase by 6 - to 8 -fold over control. These five congeners similarly induced $\mathrm{B}[a] \mathrm{P}$ hydroxylase more than PB. Furthermore these increases in 4-CBP and $\mathrm{B}[a] \mathrm{P}$ hydroxylase activity were paralleled by shifts in the peak maxima of both the CO- and EIC-difference spectra. Therefore, in addition to their PB-type characteristics, these five PCB congeners also displayed varying degrees of MC-type characteristics.

\section{DISCUSSION}

Previous studies have shown that in the PCB series only 4 strictly MCtype inducers have been identified, namely, 3,3',4,4'-tetra-, 3,4,4',5-tetra-, $3,3^{\prime}, 4,4^{\prime}, 5$-penta- and $3,3^{\prime}, 4,4^{\prime}, 5,5^{\prime}$-hexachlorobiphenyl. With one exception, the substitution of one ortho chlorine on the nucleus of the MC-type inducers does not eliminate this type of activity and results in a series of mixed-type inducers. The exceptional PCB, 2',3,4,4',5,5'-hexachlorobiphenyl, has been categorised as a novel microsomal enzyme inducer [3,4] which contrasts with its bromo analogue, $2^{\prime}, 3,4,4^{\prime}, 5,5^{\prime}$-hexabromobiphenyl, which was classified as a mixed-type inducer [19]. There is no apparent explanation for this difference.

We have recently confirmed [8] that two PCB isomers, $2,2^{\prime}, 3^{\prime}, 4,4^{\prime}, 5$ - and $2,2^{\prime}, 3,3^{\prime}, 4,4^{\prime}$-hexachlorobiphenyl, are also mixed-type inducers in contrast to the PB-type activity of $2,2^{\prime}, 4,4^{\prime}, 5,5^{\prime}$-hexachlorobiphenyl [7]. These three isomers are all di-ortho substituted PCBs derived from 3,3',4,4'-tetrachlorobiphenyl and this report compares the activity of all possible di-ortho subloss of the MC-type activity. A possible explanation of the results may be 
stituted PCB congeners derived from the 4 MC-type inducers (see Fig. 1). The only di-ortho substituted PCB derived from 3,3',4,4'-tetrachlorobiphenyl which had not been previously studied was $2,3,3^{\prime}, 4,4^{\prime}, 6$-hexachlorobiphenyl in which both ortho chloro substituents are on the same phenyl ring. This isomer enhanced microsomal NADPH-cytochrome $c$ reductase, 4-CBP hydroxylase, $\mathrm{B}[a] \mathrm{P}$ hydroxylase and DMAP $N$-demethylase activities consistent with a mixed-type induction pattern. The results indicate that for this series of PCB isomers, only those isomers which contain an isolated 2,3,4trichlorophenyl substitution are mixed-type inducers and apparently the second ortho substituent can appear on either phenyl ring.

There are three possible di-ortho substituted isomers of 3,4,4',5-tetrachlorobiphenyl, namely $2,3^{\prime}, 4,4^{\prime}, 5^{\prime}, 6-, 2,2^{\prime}, 3,4,4^{\prime}, 5$ - and $2,3,4,4^{\prime}, 5,6$-hexachlorobiphenyl, and only the latter isomer elicited effects consistent with a mixed-type inducer. The effects of structure in this series are remarkably illustrated by the successive transfer of the ortho chloro groups in $2,3,4,4^{\prime},-$ 5,6-hexachlorobiphenyl to the less substituted ring. Transfer of one ortho chloro group from this mixed inducer gives the $2,2^{\prime}, 3,4,4^{\prime}, 5$-isomer, which is a PB-type inducer, and transfer of the second ortho group gives the $2,3^{\prime}, 4,4^{\prime}, 5^{\prime}, 6$-isomer, which is the only PCB in the series which had no significant effect on any of the enzymic or spectral parameters reported in Table II.

The four di-ortho substituted heptachlorobiphenyls and two di-ortho substituted octachlorobiphenyls derived from $3,3^{\prime}, 4,4^{\prime}, 5$-penta- and $3,3^{\prime}, 4,4^{\prime}, 5,5^{\prime}$,hexachlorobiphenyl, respectively, all enhanced hepatic microsomal DMAP- $N$ demethylase ( $>2$-fold), NADPH-cytochrome $c$ reductase $(>2$-fold) and $\mathrm{B}[a] \mathrm{P}$ hydroxylase activity $(>2$-fold). With the exception of the asymmetrical $2,2^{\prime}, 3,3^{\prime}, 4,4^{\prime}, 5$-heptachlorobiphenyl, these congeners could not be distinguished from PB in their mode of induction. 2,2',3,3',4,4',5-Heptachlorobiphenyl was the only inducer in this series to enhance both $\mathrm{B}[a] \mathrm{P}$ hydroxylase ( $\sim 2 \times \mathrm{PB})$ and 4-CBP hydroxylase (6X PB) activities consistent with a mixedtype induction pattern.

The results indicate that the introduction of two ortho substituents to the nucleus of the four MC-type inducers does not eliminate this activity if one ring has a 2,3,4-trichloro substitution pattern. The only exception to this rule is $2,3,4,4^{\prime}, 5,6$-hexachlorobiphenyl which also elicited responses typical of this class of inducers. These relationships emphasize both the unusual properties of the 2,3,4-trichlorophenyl moiety and the myriad of subtle effects of structure on the activity of PCB isomers and congeners as hepatic microsomal enzyme inducers. One such example illustrates the effects of meta substituents: $2,2^{\prime}, 3,3^{\prime}, 4,4^{\prime}, 5$-heptachlorobiphenyl is a mixedtype inducer but can be converted to a PB-type inducer either by eliminating the 3 '-substituent to give $2,2^{\prime}, 3,4,4^{\prime}, 5$-hexachlorobiphenyl or by its transfer to the $5^{\prime}$-meta position to give $2,2^{\prime}, 3,4,4^{\prime}, 5,5^{\prime}$-heptachlorobiphenyl. Similarly, although $2,3,4,4^{\prime}, 5,6$-hexachlorobiphenyl is a mixed-type inducer, the addition of one or two meta chloro substituents to give $2,3,3^{\prime}, 4,4^{\prime}, 5,6$ hepta- and $2,3,3^{\prime}, 4,4^{\prime}, 5,5^{\prime}, 6$-octachlorobiphenyl, respectively, results in the 
loss of the MC-type activity. A possible explanation of the results may be associated with the stereochemical conformations of these compounds in solution which would presumably affect their capacities to bind to the cytosolic receptor protein which plays a critical role in hepatic microsomal enzyme induction [20-22]. The crystal structures, conformational properties and the receptor-binding characteristics of these PCB congeners are currently being investigated.

\section{ACKNOWLEDGEMENTS}

The authors wish to thank the Research Programs Directorate, Health and Welfare Canada (606-1444-X), the National Cancer Institute (5 R01CA21814-02), the National Sciences and Engineering Research Council of Canada and the Environmental Protection Agency (CR 806928010) for financial assistance.

\section{REFERENCES}

1 A. Parkinson, L. Roberston, L. Safe and S. Safe, Polychlorinated biphenyls as inducers of hepatic microsomal enzymes: structure-activity rules, Chem.-Biol. Interact., 30 (1980) 271.

2 A. Parkinson, R. Cockerline and S. Safe, Polychlorinated biphenyl isomers and congeners as inducers of both 3-methylcholanthrene and phenobarbitone-type microsomal enzyme activity, Chem.-Biol. Interact., 29 (1980) 277.

3 A. Parkinson, L.W. Robertson, S. Bandiera, K. Riley and S. Safe, Evidence that $2^{\prime}, 3,4,4^{\prime}, 5,5^{\prime}$-hexachlorobiphenyl is neither a phenobarbitone- or 3-methylcholanthrene-type inducer of cytochrome $P-450$, manuscript in preparation.

4 A. Parkinson, L.W. Robertson, S. Bandiera, L. Safe, L. Uhlig and S. Safe, Further characterization of the mode of cytochrome P-450 induction by $2^{\prime}, 3,4,4^{\prime}, 5,5^{\prime}$-hecachlorobiphenyl: Additivity with pregnenolone-16 $\alpha$-carbonitrile and non-additivity with isosafrole, manuscript in preparation.

5 A.P. Alvares, Stimulatory effects of polychlorinated biphenyls (PCB) on cytochromes P-450 and P-448 mediated microsomal oxidations, in: V. Ullrich (Ed.), Microsomes and Drug Oxidations, Pergamon Press, Inc. Oxford, 1977, p. 476.

6 M.D. Stonard and J.B. Greig, Different patterns of hepatic microsomal enzyme activity produced by administration of pure hexachlorobiphenyl isomers and hexachlorobenzene, Chem.-Biol. Interact., 15 (1976) 365.

7 J.A. Goldstein, J.R. Hass, P. Linko and D.J. Harvan, 2,3,7,8-Tetrachlorodibenzofuran in a commercially available $99 \%$ pure polychlorinated biphenyl isomer identified as the inducer of hepatic cytochrome P-448 and aryl hydrocarbon hydroxylase in the rat, Drug. Metab. Dispos., 6 (1978) 258.

8 A. Parkinson, L.W. Robertson and S. Safe, Hepatic microsomal enzyme induction by $2,2^{\prime}, 3,3^{\prime}, 4,4^{\prime}$ - and $2,2^{\prime}, 3^{\prime}, 4,4^{\prime}, 5$-hexachlorobiphenyl, Life Sci., 27 (1980) 2333.

9 J.I.G. Cadogan, A convenient new method of aromatic arylation, J. Chem. Soc. (Lond.) (1962) 4257.

10 A. Parkinson, R. Cockerline and S. Safe, Induction of both 3-methylcholanthrene and phenobarbitone-type activity by a single polychlorinated biphenyl isomer, Biochem. Pharmacol., 29 (1980) 259.

11 A. Parkinson and S. Safe, The detection of enzyme induction by rat liver microsomes prepared by isoelectric precipitation, J. Pharm. Pharmacol., 31 (1979) 444.

12 O.H. Lowry, N.J. Rosebrough, A.L. Farr and R.J. Randall, Protein measurement with Folin phenol reagent, J. Biol. Chem., 193 (1951) 265. 
$13 \mathrm{~T}$. Omura and R. Sato, The carbon monoxide-binding pigment of liver microsomes, I. Evidence for its haemoprotein nature, J. Biol. Chem., 239 (1964) 2370.

14 I. Raw and H.R. Mahler, Studies of electron transport enzymes. III. Cytochrome $b_{5}$ of pig liver mitochondria, J. Biol. Chem., 234 (1959) 1867.

15 J.W. De Pierre, M.S. Moron, K.A.M. Johannesen and L. Ernster, A. reliable, sensitive and conventient radioactive assay for benzpyrene monnoxygenase, Anal. Biochem., 63 (1975) 470.

16 S. Nesnow, W.E. Fahl and C.R. Jefcoate, An improved radiochemical assay for benzo[a]pyrene monooxygenase, Anal. Biochem., 80 (1977) 258.

17 A. Parkinson, L. Copp and S. Safe, The utility of the microsomal 4-chlorobiphenyl hydroxylase enzyme assay in distinguishing between phenobarbitone- and 3-methylcholanthrene- induced microsomal monooxygenases, Anal. Biochem., 105 (1980) 65.

18 G.W. Dunnett, New tables for multiple comparisons with a control, Biometrics, 20 (1964) 482.

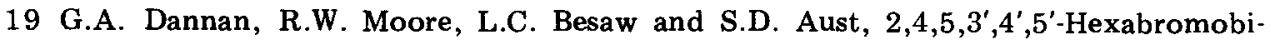
phenyl is both a 3-methylcholanthrene- and a phenobarbital-type inducer of microsomal drug metabolizing enzymes, Biochem. Biophys. Res. Commun., 85 (1978) 450.

20 A. Poland, E. Glover and A.S. Kende, Stereospecific, high affinity binding of $2,3,7,8-$ tetrachlorodibenzo-p-dioxin by hepatic cytosol, J. Biol. Chem., 251 (1976) 4936.

21 A.B. Okey, G.P. Bondy, M.E. Mason, G.F. Kahl, H.J. Eisen, T.M. Guenthner and D.W. Nebert, Regulatory gene product of the Ah locus, J. Biol. Chem., 254 (1979) 11636.

22 W.F. Greenlee and A. Poland, Nuclear uptake of 2,3,7,8-tetrachlorodibenzo-p-dioxin in C57BL/6J and DBA/1J mice, J. Biol. Chem., 254 (1979) 9814. 